\title{
PSO based Directional Relay Parameter Tuning for Smart Grid Systems Protection
}

\author{
Praveen kumar Raghuvanshi ${ }^{1}$, \\ ${ }^{1}$ ABES Engineering College, Ghaziabad, India, pankaj681@ rediffmail.com
}

\begin{abstract}
Power system grid are upgraded by enhancement of directional over-current-relays (DOCRs) setting is a basic issue in electrical designing. The smart grid advancement model of the issue end up being non-direct and rather controlled wherein setting especially time dial setting (TDS) and plugging setting (PS) of each hand-off are set over a choice factors; the total of the working on all the essential transfers, which are anticipated to work that enable to clear the issue in their relating zones, considered as main objective. In the predominant analyze, demonstrate thought about especially IEEE eight-bus power syatem. To comprehend the problem, we have connected PSO based smart mechanism to upgrade the normal power system grid to smart grid. The outcome are a contrasted and the traditional arrangement of intelligent guideline followed by relays; the numerical outcome demonstrate that the changed calculation outflank or perform at standard with different calculations. In light of the intelligent coordination result acquired on the investigations, the proposed optimized enhancement set of principle can be utilized to compute the setting of the directional overcurrent transfer in a distribution community with allotted generation demand of smart grid. The proposed set of rule has shown to have the potential to keep selectivity among the relay being coordinated and limit the running time of the primary relay for close-in 3-phase faults.
\end{abstract}

Keywords: Optimization, PSO, DOCR, power system protection

\section{INTRODUCTION}

Hand-off Coordination in a tremendous dissemination framework with more than one cross sections and bidirectional power feed transforms into Complex for design engineers of smart grids. Manual and diagram rule based methodologies had been executed productively in little power contraption. In a major circulation device direct and non-straight programming based absolutely advancing strategies are actualized for transfer coordination for smart6 grids. In this works of art streamlining methods are executed for most appropriate co-appointment of directional overcurrent transfers. This theory talks about the use of Particle Swarm Optimization (PSO) calculation for most worthwhile coordination of DOCR transfers in a 8 bus power [2] machine system. Blend of essential and reinforcement hand-off is chosen by means of the utilization of far and close stop vector of shape, to maintain a strategic distance from miscoordination of transfers. Coordination of DOCR is inspected for IEEE 8 bus structures the utilization of the PSO for protection of smart grid. Likewise, the objective trademark is changed to improve the working time among reinforcement and essential transfers. The results are contrasted and the improved estimations of Time dial set parameter and Plugging set parameter esteems acquired from mainstream conventional methodology. The proposed calculation dependent on PSO offers surest coordination edge and no mis-coordination between number one and reinforcement sets for intelligent protection of smart grid. Results additionally are demonstrated the utilization of recreation created on MATLAB programming $[6,7,8,10]$.

Low esteem and straightforwardness to execute are the merits of overcurrent transfer programming for circulation gadget insurance. For bidirectional quality float feeders directional sort of overcurrent transfers are utilized for assurance application. In the event that any hand-off neglects to react the supports by each other transfer. The task of primary relay and back-up relay hand-off works after a beyond any doubt time edge. In this way, the transfers are set in this sort of style to separate the base broken part of vitality network. Overcurrent transfers are utilized as both essential and reinforcement security for intensely [11] fit and multi-supply control network. Hand-off Coordination in a coincided vitality arrange in very repetitive and time ingesting issue. Prior coordination of directional overcurrent relay (DOCRs) changed into achieved physically, which transformed into very time synchronization. The utilization of smart grid has the hand-off coordination has remembered assurance building from cumbersome figuring. Essentially there are two systems are utilized for DOCR, traditionally reasoning and parameter streamlining methods.

Producing power ought to no longer threaten the environment. It ought to advantage the surroundings in a single manner or the alternative. Over the closing five years non traditional resources has come to be a leading renewable strength funding destination [1]. The authorities has incentivized initiatives aimed at addressing the demanding situations of electricity 
need, economic increase, the international carbon footprint and weather modifications using smart grids.

Stuck in an unfortunate situation of planning DOCR in power structures is said and explained inside the system of advancement hypothesis. The proposed strategy decides the "premier" way to deal with this coordination issue in a savvy and green way, by utilizing proclaiming the inconvenience as a parameter advancement issue, and fixing it the use of productive improvement procedures. Here the improvement of Time Dial Setting and limited capacity were given from Linear programming with Large-Scale: Interior Point in Matlab has been executed by method for Particle swarm Optimization strategy coded in MATLAB. It is appropriate to state directly here that the Optimization strategy displayed on this works of art additionally can be connected to the issue of most noteworthy quality coordination of protecting transfers beside directional over present current value transfers (e.g. Separation transfers [9]). The enhancement approach and its particularization to the instance of directional over current transfers depend on PSO.

\section{RELATED WORK}

DOCR are utilized for the insurance of intensity transmission and appropriation frameworks. Such transferring is utilized in number one wellbeing of ring type topology of power grids contraption if indistinguishable criticalness of fault at forefront streams on both course [1] or in optional assurance in power structures [2]. Transfers region shrewd recognize one of a kind flows by means of a similar fault condition. This section mindfulness on transfer coordination issue based thoroughly articles evaluation that portrays the methods to decide the hand-off activities smart grid protection scheme to furnish productive coordination of relay with least time delay [3].

The most extreme basic task when putting in DOCRs at the framework is picking their appropriate settings with the end goal that their crucial securing capacity is met underneath the prerequisites of affectability, selectivity, unwavering quality and pace [4]. The over current hand-off coordination in appropriation contraption systems is in all respects colossally requirement improvement issues of pursuing target for advanced vitality machine dependability. A few articles over count of the time dial and rated current [12] ((TDS and Ipu) setting of the DOCRs is the center of the coordination.

A few written works have proposed inexhaustible innovation which may be thought about as smooth supply of vitality and surest utilization of these recourses limit natural effects, produce the insignificant optional waste and feasible basically dependent on present current value and financial objectives of smart grid. These advantages are ordinarily appropriated in nature and immediately coordinated at dissemination stages. Expanding infiltration of the dispensed vitality recourses in dissemination power organize make additional operational and control inconveniences [5]. In this manner new insurance coordination plot in [12] smart grids are required for providing the sufficient security coordination for administered vitality assets related electric controlled power network. Because of this streamlining of directional over-flow hand-off in DOCR settings is a vital problem inside the electric quality system for smart grids [13]. The enhancement rendition of the inconvenience is by all accounts non-straight and truly compelled in which settings especially time dial settings (TDS) and plugging settings (PS) of each DOCR are thought about as decision variable; the total of running occurrences of all essential transfers, which can be anticipated to work a decent method to clean the fault condition in their relating zones is contemplated as target work for a smart grid. In present paper work [14], three models are contemplated to be specific IEEE-three bus power system demonstrate, IEEE-4 bus power system model and IEEE-6 bus version. The purpose of this review is discover the destiny scope of relay coordination application for dispensed strength sources related distribution system.

\section{METHODOLOGY}

The finest coordination hassle of DOCRs in smart grid is the use of optimization method comprises of limiting a goal work (execution work) issue to certain coordination criteria and limits on inconvenience factors. The DOCR, which should work first to clean the fault condition, is alluded to as the essential hand-off in smart grid [20]. A fault condition near DOCR is known as the close in fault condition for the handoff and a fault condition at the other quit of the line is known as a far-bus power system [16] fault condition for the handoff. Ordinarily, objective capacity in coordination inquire about is established in light of the fact that the summation of working occasions of all essential DOCRs, reacting to clean all shut in and far bus power system issues in smart grid. The objective component is portrayed as pursues [17]:

Minimize
$\sum_{I=1}^{N_{d}} T_{\text {pri_cl_in }}^{i}+\sum_{j=1}^{N f a r} T_{\text {priffor_bus }}^{j} \quad$ OBJ

where, $\mathrm{N}_{\mathrm{cl}}$ i number of relay responding for close-in fault. $\mathrm{N}_{\text {far }}$ $i$ stature of relay responding for far-bu fault. $T_{\text {pri_cl_in }} i$ primary relay operating time for close-in fault. $T_{\text {pri_far_bu }} i$ primary relay operational time for far-bus fault. The constraint are a follows [18]:

(1) Bound on variable TDSs $T D S_{\text {min }}^{i} \leq T D S^{i} \leq T D S_{\text {max }}^{i}$, where $i$ varies from 1 to $N_{c l}$. $T D S_{\text {min }}^{i}$ is the lower limit and $T D S_{\text {max }}^{i}$ is the upper limit of $T D S^{i}$ These limits are 0.05 and 1.1 , respectively.

(2) Bound on variable PSs $P S_{\text {min }}^{i} \leq P S^{i} \leq P S_{\text {max }}^{i}$, where $i$ varies from 1 to $N_{c l}$. $P S_{\text {min }}^{i}$ is the lower limit andPS $S_{\text {max }}^{i}$ is the upper limit of $P S^{i}$

These are 1.25 and 1.50 , respectively.

(3) Limit on primary operation times

Thi constraint impose constraint on each term of objective function to lie between 0.05 and 1.0.

(4) Selectivity constraint for all relay pairs

$\mathrm{T}_{\text {backup }}-\mathrm{T}_{\text {primary }}-\mathrm{CTI} \leq 0$

$\mathrm{T}_{\text {backup }} \mathrm{i}$ the operating time of backup relay, $\mathrm{T}_{\text {primary }} \mathrm{i}$ operating time of main relay and CTI i coordinating time interval. 


\section{A. Model 1-the IEEE 8-bu model for smart grid:}

For the association issue of IEEE 8-bus power system demonstrate, estimation of everything about and $\mathrm{N}_{\text {far }} \mathrm{i} 14$ (equivalent to number of DOCR or twofold the lines). A need be, there are 28 choice factor (two for each DOCR) in thi issue for example $\mathrm{TDS}_{1}-\mathrm{TDS}_{14}$ and $\mathrm{PS}_{1}-\mathrm{PS}_{14}$. The 8-bus smart grid power system framework can be pictured a appeared in Fig. 1. Target work (OBJ) to be limited a given by [19].

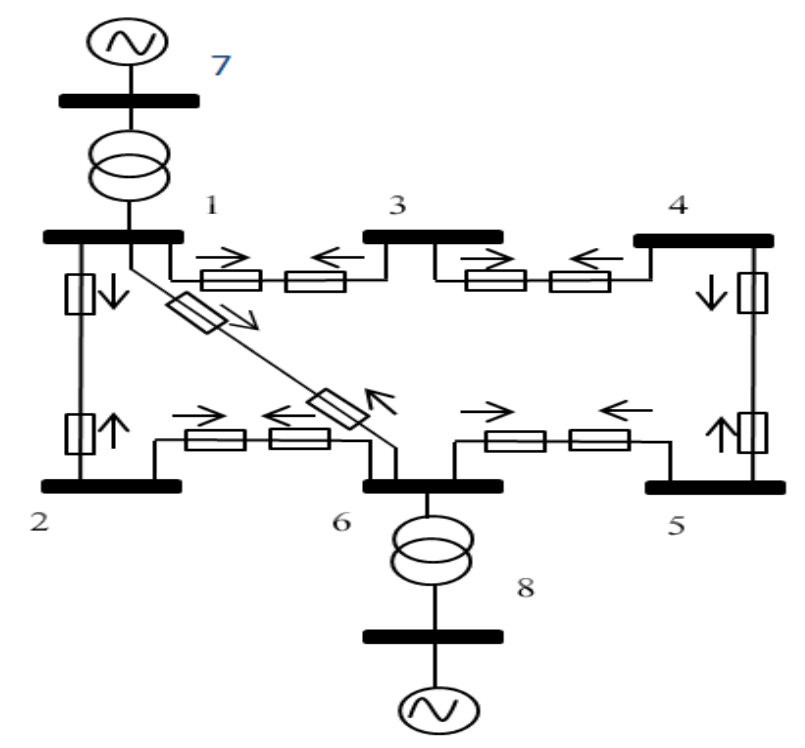

Figure 1: Eight Bu System

$$
O B J=\sum_{i=1}^{6} T_{p r i \_c l \_i n}^{i}+\sum_{j=1}^{6} T_{p r i f f o r \_b u s}^{j}
$$

Where

$$
\begin{gathered}
T_{\text {pri_cl_in }}^{i}=\frac{0.14 * T D S^{i}}{\left(\frac{a^{i}}{P S^{i} * b^{i}}\right)^{0.02}-1} \\
T_{\text {pri_cl_in }}^{i}=\frac{0.14 * T D S^{j}}{\left(\frac{c^{i}}{P S^{i} * b^{i}}\right)^{0.02}-1}
\end{gathered}
$$

The value of $a^{i}, b^{i}, c^{i}$ and $d^{i}$ are constant. constraint for the model boundarie on variable TDSs

$$
\begin{aligned}
& T D S_{\min }^{i} \leq T D S^{i} \\
& \leq T D S_{\text {max }}^{i}, \text { where, i varies from } 1 \text { to } 14\left(N_{c l}\right)
\end{aligned}
$$

Bound on variable PSs:

$$
\begin{aligned}
& P S_{\min }^{i} \leq P S^{i} \\
& \leq P S_{\max }^{i} \text {, where, } i \text { varies from } 1 \text { to } 14\left(N_{c l}\right)
\end{aligned}
$$

Limit on primary operation times:

Thi restraint impose constraint on each term of objective function to lie between 0.05 and 1.0. Selectivity constraint are

$$
T_{\text {backup }}^{i}-T_{\text {primary }}^{i}-C T I \geq 0
$$

$\mathrm{T}_{\text {backup }} \mathrm{i}$ the operating time of backup relay and $\mathrm{T}_{\text {primary }} \mathrm{i}$ the operating time of primary relay. Value of coordinating time interval (CTI) i 0.3. Here

$$
\begin{aligned}
T_{\text {backup }}^{i} & =\frac{0.14 * T D S^{p}}{\left(\frac{e^{i}}{P S^{p} * f^{i}}\right)^{0.02}-1} \\
T_{\text {primary }}^{i} & =\frac{0.14 * T D S^{q}}{\left(\frac{g^{i}}{P S^{q} * h^{i}}\right)^{0.02}-1}
\end{aligned}
$$

The $\mathrm{p}, \mathrm{q}, \mathrm{e}^{\mathrm{i}}, \mathrm{f}^{\mathrm{i},} \mathrm{g}^{\mathrm{i}}$ and $\mathrm{h}^{\mathrm{i}}$ are constants.

In Fig. 2, $x_{1}, x_{2}$ and $x_{3}$ all have difference distance from itself to global best position. $X_{1}$ drop within the radiu of $(0.5-a c)^{*}$ $\mathrm{FD}_{\mathrm{d}}$. The distance from $\mathrm{x}_{2}$ to global best position $\mathrm{i}$ between $(0.5-\mathrm{ac})^{*} \mathrm{FD}_{\mathrm{d}}$ and $(0.5+\mathrm{ac})^{*} \mathrm{FD}_{\mathrm{d}} \cdot \mathrm{x}_{3}$ drop beyond the radiu of $(0.5+\mathrm{ac})^{*} \mathrm{FD}_{\mathrm{d}}$ in DAPSO1. In DAPSOs, we define the "long distance" a the distance from the particle to the global best beyond $(0.5+\mathrm{ac})^{*} \mathrm{FD}_{\mathrm{d}}$ and the "short distance" a the distance from the particle to the global best i smaller than $(0.5-\mathrm{ac})^{*}$ $\mathrm{FD}_{\mathrm{d}}$. In DAPSO1, The particle a long way far from the worldwide high-quality must take delivery of larger price of velocity so it may discover an unknown region, while those near the worldwide first-rate ought to receive smaller value of speed so that it $i$ able to make the most the neighbourhood of the worldwide high-quality.

In DAPSO2, if there had been many suitable solutions from the global fitness function, then the velocities should be given a larger priority. If there were many particles near from the global great position, then the velocities should be given a smaller cost. DAPSO1 most effective adjust the rate of the positive particle, however in DAPSO2, the velocitie of all particle are adjusted collectively [21].

The preferred go with the flow of DAPSO and the flowchart of DAPSO are proven a follows.

Step 1. Initialization of a population of particle with random position and velocities

Step 2.Evaluation of particles.

Step 3. Calculate the distance from each particle to the global best position and save the farthest distance in the memory.

Step 4. Adjust particle' velocity according to it distance from itself to the global best position.

Step 5. Update particle' position by the adjusted velocity.

Step 6. Repeat Step.2 Step.5 until termination criteria are met. 
Praveen kumar Raghuvanshi, International Journal of Emerging Trends in Engineering Research, 8(9), September 2020, 5214 - 5219

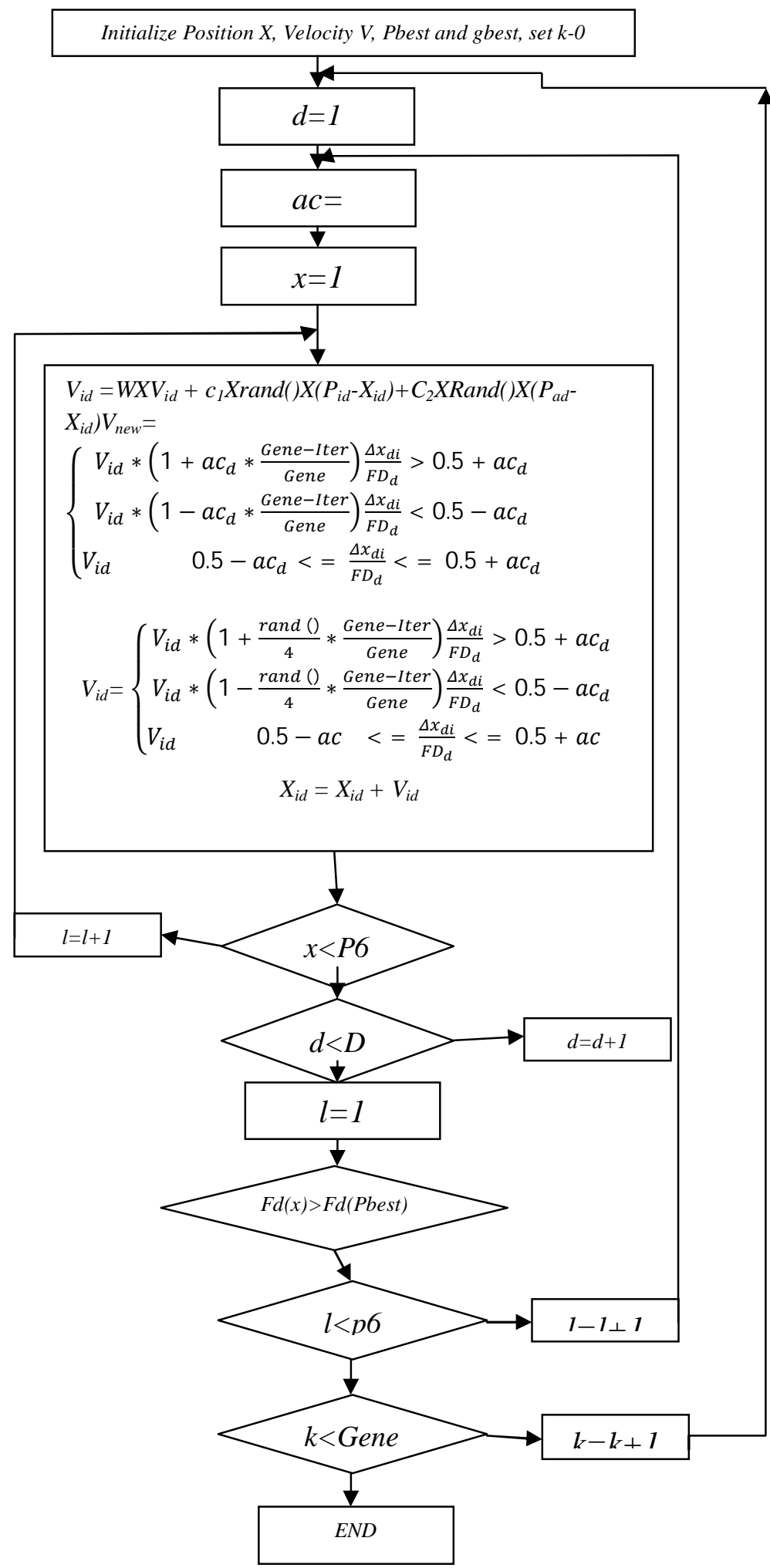

Figure 2: Flowchart of DAPSO

\section{RESULT AND DISCUSSION}

The optimized PSO cases is demonstrated in the parent given underneath, wherein the near stop $3 \phi$ fault condition is considered. Power transfer over 8 bus smart grid is associated with an outside network this is displayed by utilizing 400 MVA brief-circuit potential. Some examination named this machine as a 6-bus power system smart grid, because of the reality bus- 7 and bus- 8 (Shown in fig 3) are identified with the creating generators and do now not have any hand-off. The to be had set of the discretized plug-setting (PS) is $0.5,0.6,0.8,1.0,1.5,2,2.5$. In spite of the fact that this check case has little measurement, it's been seen that it is extremely hard to get possibly and most gainful solution. The CT proportions (CTRs) and the $3 \phi$ cut off current value for every $\mathrm{P} / \mathrm{B}$ pair of DOCRs are given underneath

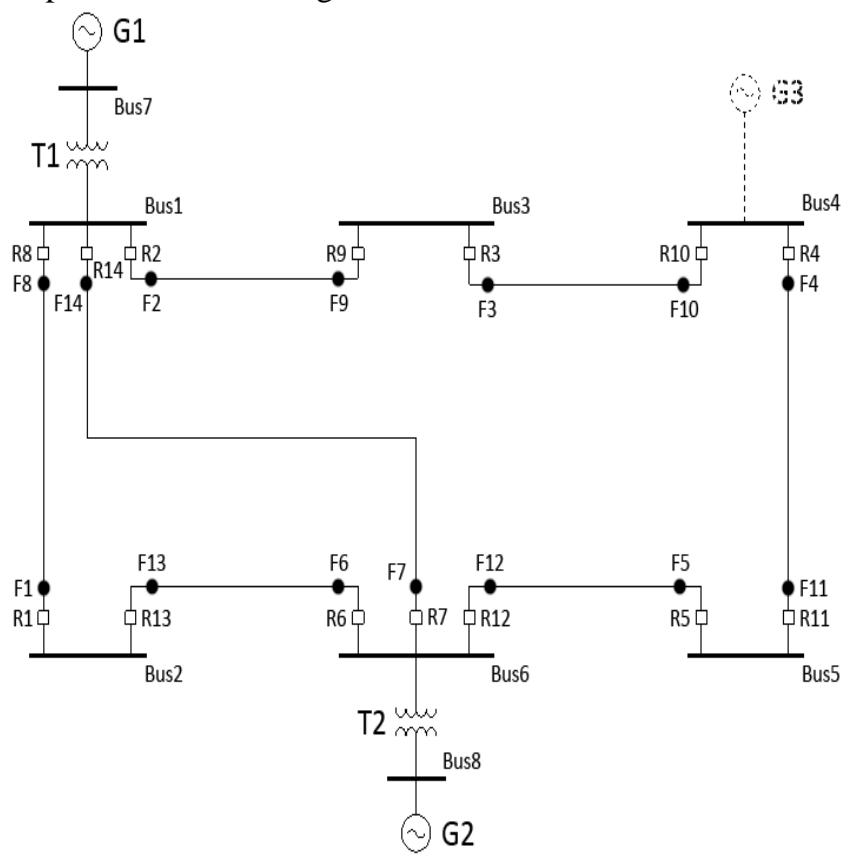

Figure 3: 8 Bus system

The optimization process is run for 100 iteration and the final value of above mentioned fitness function is observed to be decreasing a shown in figure 4 and figure 5 .

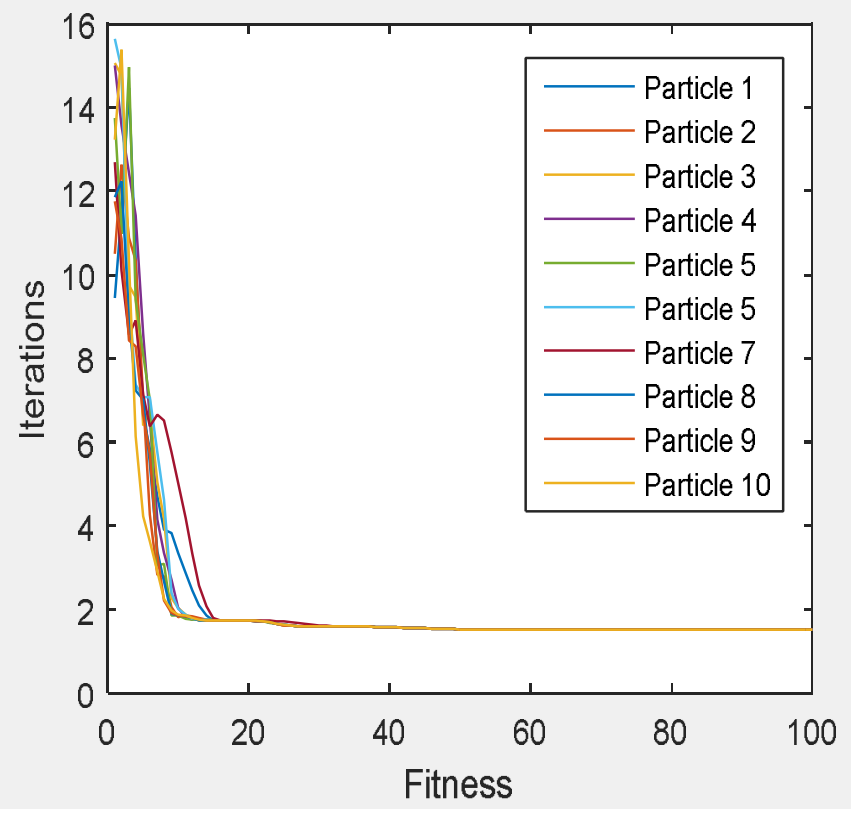

Figure 4: Convergence plot of PSO fitness cost function. 


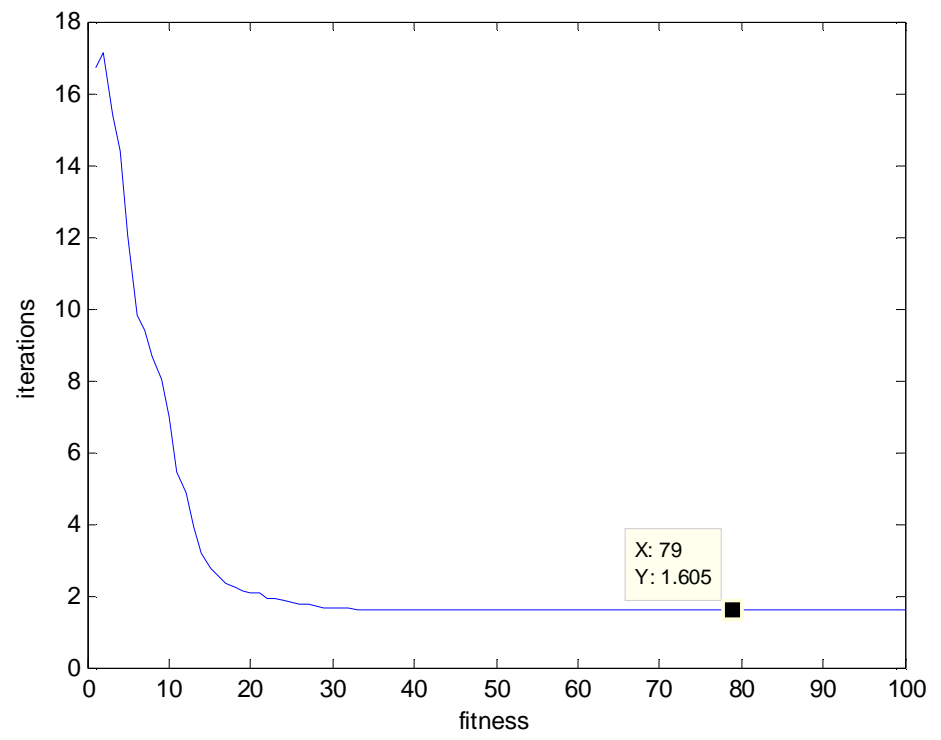

Figure 5: Convergence plot of PSO average fitness cost function

After the finish of optimization proces the optimized solution in term of TD and $\mathrm{P}$ are shown in figure 6.

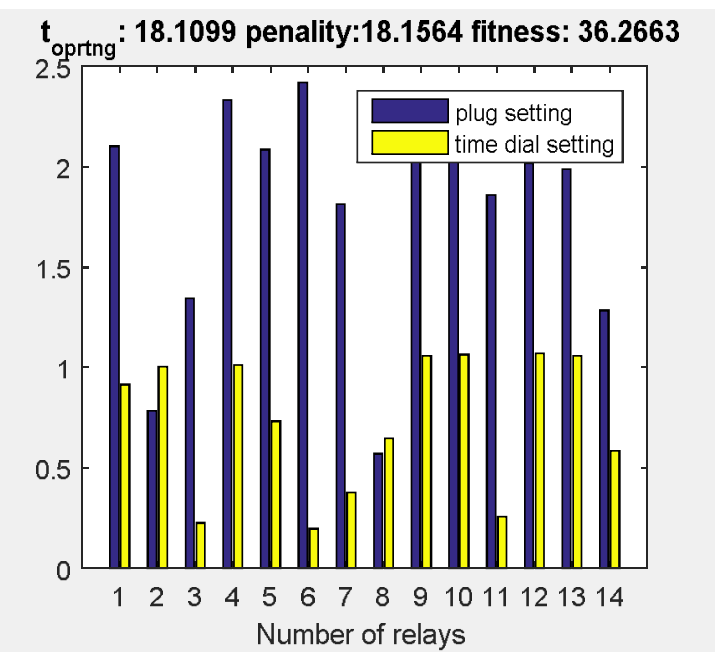

Figure 6: Penalty time and plug setting value for all relays

\section{CONCLUSION}

Coordination of directional over-flow hand-off (DOCR) in smart grid is an oftentimes emerging issue in the field of electrical designing, which can be detailed as a streamlining issue. The numerical model of the issue is exceptionally mind boggling and non-direct in nature, subject to different imperatives, and requires refined improvement procedures for its answer. In this work, an endeavor is made to illuminate the IEEE 8-bus power system development for protection of smart grid show with the assistance of advancement approach and with changed wellness condition rendition. Improved variants recommended here consider time and punishment limitations both and used to take care of the previously mentioned DOCR issue. Observational investigation of numerical outcomes gotten by PSO plans and ordinary calculations demonstrate the ability of the proposed calculations. Besides PSO streamlining plans require just a single control parameter for example the hybrid rate, though the vast majority of different strategies have more than one control parameters, which are to be tweaked for the fruitful execution of a calculation. Among the PSO, the calculation configuration would require the utilization of quick combination approach for tackling the mind boggling kind of issues referenced in the present examination for smart grids.

\section{References}

[1] P.M. Anderson, Power system Protection. Newyork: McGraw-Hill, 1999.

[2] Warrington, ARC, The Protective Relays. Theory and Practice, John Wiley 8 Sons, New York, 1969.

[3] Westinghouse Electric Corp., Applied Protective Relaying, Westinghouse Electric Corp., Newark, NJ. 1979.

[4] General Electric Co. Measurements, Protective Relay Application Guide, GEC, United Kingdom, 1975.

[5] A. J. Urdenta, et al. "Optimal Coordination of Directional Over current Relay in Interconnected Power Systems", IEEE Trans. on Power Delivery, Vol. 3, July 1988, pp. 903-911.

[6] Quanming Yue, Feipeng Lu, Weiyong Yu, and Jie Wang "A Novel Algorithm to Determine Minimum Break Point Set for Optimum Cooperation of Directional Protection Relay in Multiloop Networks" IEEE Transaction on power delivery, Vol. 21, pp.1114-1119,July2006

[7] N. A. Laway, H. O. Gubta, "A Method for Coordination of Over current Relay in an Interconnected Power Systems", IE Journal, Vol. 74,August1993,pp.59-65..

[8] Urdaneta, AJ."Minimax Optimization for Power System Control: A Multiple Objective Approach," PhD Dissertation, Case Western Reserve University,

[9] IEC Standard, Single Input Energizing Quantity Measuring Relay with Dependent Specified Time, Publication No. 255-4, 1976.

[10] C.W.So, K.K.Li "Application of genetic algorithm for overcurrent relay coordination", IEE 6th international conference on development in power system protection, Nottingham,

March 1997, pp 66-69

[11] B.Chattopadhyay, M.S.Sachedev and T.S.Sidhu,"An On Line relay Coordination Algorithm for Adaptive protection using Linear Programming Techniuqe", IEEE Transaction on power

Delivery, Vol. 11, No.1, January 1996, pp.165-173

[12] J.Kennedy and R. Eberhart, "Particle swarm optimization" in Proc. IEEE Neural Network Conf.Piscataway, NJ, 1995, pp 1942-1948

[13] Y.Shi and R.Eberhart," A modified particle swarm optimizer" in Proc IEEE Int.Conf, on Evolutionary Computation, 1998, pp 69-73

[14] C.H. Lee and C.R. Chen, "Using genetic algorithm for overcurrent relay coordination in industrial power system," in International conference on intelligent system application to power systems, 2007.

[15] S.S. Rao, in Engineering optimization: theory and practice, John wiley and sons., 2009, pp. 1-21. 
Praveen kumar Raghuvanshi, International Journal of Emerging Trends in Engineering Research, 8(9), September 2020, 5214 - 5219

[16] Anurag, R. Sharma, " Modern Trends on Image Segmentation for Data Analysis- A Review", International Journal of Research and Development in Applied Science and Engineering, Volume 20, Issue 1, 2020.

[17] R. Sharma, Anurag, " Load Forecasting using ANFIS A Review", International Journal of Research and Development in Applied Science and Engineering, Volume 20, Issue 1, 2020.

[18] Anurag, R. Sharma, " Load Forecasting by using ANFIS", International Journal of Research and Development in Applied Science and Engineering, Volume 20, Issue 1, 2020.

[19] R. Sharma, Anurag, " Detect Skin Defects by Modern Image Segmentation Approach, Volume 20, Issue 1, 2020.

[20] Young Soo Jang et. al., "Development of the costeffective, miniaturized vein imaging system with enhanced noise reduction", International Journal of Advanced Trends in Computer Science and Engineering, Volume 8, No.6, November - December 2019.

[21] Irma T. Plata1, et. al., "Development and Testing of Embedded System for Smart Detection and Recognition of Witches' Broom Disease on Cassava Plants using Enhanced Viola-Jones and Template Matching Algorithm", International Journal of Advanced Trends in Computer Science and Engineering, Volume 8, No.6, Volume 8, No.5, September October 2019. 